\title{
Kurumsal İktisat Yaklaşımları Bă̆lamında Kurumsal Yapı-Ekonomik Büyüme İlişkisi: Teori ve Uygulama ${ }^{1}$
}

\author{
YAhYa CAN DuRA (10) ${ }^{2}$ \\ Baß̧vuru: 12.03.2019; Düzenlenme: 12.04.2019; Kabul: 13.04.2019
}

\section{Giriş}

$\mathrm{Bu}$ tez, egemen iktisat ideolojisine farkl bir bakış açısı geliştirmiş olan ve alternatif iktisat tanımı yapan bir iktisat ekolünü ele almaktadır. Türkiye'deki iktisat literatüründe çok nadir olarak ele alınan Asıl Kurumsal İktisat yaklaşımının tarihsel bir inceleme metodolojisi izlenerek çözümlenmesi ve kurumsal yapı ile ekonomik büyüme arasındaki olası ilişkilerin ortaya konulması tezin temel amacidır.

\section{Tezin konusu}

Tezin konusu, Kurumsal İktisat ekolünün hem orijinal hem de yeni versiyonlarını karşılaştırmalı analizinin yapılmasını, kurumsal yapı ölçüm yöntemlerinin ortaya konulmasinı ve bu kapsamda kurumsal yapr ile ekonomik büyüme ilişkisinin çözümlenmesi ve farkl kurum parametrelerinin ekonomi açısından öneminin belirlenmesini kapsar.

1 İktisat Anabilim Dalı Doktora Tezi, Eskişehir Osmangazi Üniversitesi Sosyal Bilimler Enstitüsü, 2018. Danışman: Doç. Dr. Füsun Yenilmez

2 İçişleri Bakanlığı Planlama Uzmanı - CGAP (Uluslararası Kamu Denetçisi)

\section{Tezin alan içindeki yeri ve önemi, farklı yönleri}

Tez, kurumsal iktisadı sadece yeni ve popüler formuyla ele almamış olması ve kurumsal ekolün kökenlerine inerek, esasen asıl ve yeni kurumsal iktisat akımları arasındaki derin uçurumu da ortaya koyma gayreti içerisinde olması ile literatürde bu alanda ağırlıklı olarak yeni kurumsal ekol bakış açısından yapılan çalışmalardan ayrılır.

Ayrica kurumsal yapı parametreleri ile ekonomik büyüme ilişkisini ortaya koymaya yönelik yaklaşımı da tek boyutlu değildir. Aynı anda birçok farklı indeks kullanarak, ekonomik büyüme ile bu indekslerin kurumsal yapı parametreleri arasındaki ilişki, bunun gücü ve yönü tespit edilmeye çalışılmıştır. Farklı indeksler kullanılarak, indekslerin açıklayıcı güçleri ve birbirleriyle mukayesesi de mümkün hale gelmiştir. Tez bu özellikleriyle diğer çalışmalardan daha farklı bir uygulama bölümüne sahiptir.

\section{Tezin kısa özeti}

İktisat bilimine yönelik bir "olması gereken" tarifi yapan Kurumsal İktisat ekolü, ekonomiyi topyekûn kurumsallaşmış bir süreç olarak görerek, yerleşik iktisattan ayrılmıs ve adeta yeni bir iktisadın mümkün olabileceğini göstermiştir. Bunu

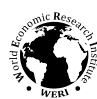


gerçekleştirirken de, yerleşik iktisadın yöntemlerine ve varsayımlarına adeta bir savaş açmıştır. Çoğu zaman sadece yerleşik iktisat eleştirisiyle var olduğu düşünülen Kurumsal İktisat, özünde orijinal birçok kavramı ve olguyu iktisat yazınına kazandırmış, bunları geliştirmiş, iktisat biliminin olgunlaşmasını ve özüne yani bir sosyal bilime dönmesini sağlayıcı bir rol üstlenmiştir.

Literatürde Kurumsal İktisada ilişkin incelemeler ağırlıklı olarak iki boyutta yapılmaktadır: Orijinal-Asıl Kurumsal İktisat ile Yeni Kurumsal İktisat. Ancak, ekoller arasındaki bu kırılma, arzu edilen bir süreç olarak değerlendirilmemektedir. Yeni Kurumsal İktisat, benimsediği yöntemler, varsayımlar ve bakış açısı itibariyle Asıl Kurumsal İktisadın yöntemsel açıdan bir takipçisi değildir. Yeni Kurumsal İktisat bu noktada Asıl Kurumsal İktisadın bir takım kavramlarını ve yöntemlerini kullanarak, yer yer de onları dönüstürerek varlığını hissettirmiştir. Özellikle kurum kavramını iktisadi analizlere yoğun şekilde dâhil ederek, yerleşik iktisadın aşırı soyut yöntemlerinin açmazlarını gidermeye çalışmış ve bu noktada kurumsalcı yaklaşımları bir manivela olarak kullanmıştır.

Tezde, kurumlar/kurumsal yapı ile ekonomik büyüme ilişkileri Kurumsal İktisadın tarihsel birikimi temelinde ve ampirik bir analiz ile ortaya konulmuştur. Sonuçlar, yerleşik iktisadın ve onun teorilerinin/yöntemlerinin ülkelerarası gelişmişlik farklılıklarının giderilmesinde etkin sonuçlar vermediği gerçeğinin, kurumlara dayalı yaklaşımların önemini arttırdığı yönündedir. Yeni Kurumsal İktisat akımı bu noktada kurumları bir araç olarak kullanarak, soyut klasik iktisada, dinamik bir görünüm vermektedir. Bunun için de farklı ekonometrik tekniklerin, farklı veri tabanlarının ve indekslerin kullanıldığ ampirik analizler yapmaktadır. Bu tezde ayrıca, kurumsal yapı ile ekonomik büyüme arasındaki ilişkiye ve kurumsal yapıyı ölçen indekslerin anlamlılığına ilişkin olarak önemli sonuçlar elde edilmiştir: Heritage İndeksine kıyasla, Fraser İndeksi ile Basın

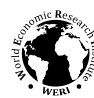

Özgürlüğü genel indeksinde temsil edilen kurumsal göstergelerin ekonomik büyüme ile ilişkisinin tüm gelir grupları için hem istatistiksel olarak hem de beklenen etki itibariyle daha güçlü olduğu görülmüştür. Bu sonuçlar çerçevesinde ekonomik özgürlükleri farklı yöntem ve parametrelerle ölçen Heritage ve Fraser İndeksleri arasında Fraser'ın öne çıktığı ve büyüme ilişkisi açısından daha anlamlı bulguları verdiği tespit edilmiştir.

\section{Tezde işlenen konular}

Tez üç ana bölüm üzerine inşa edilmiştir. İlk olarak tarihsel, kavramsal ve metodolojik boyutlarıla kurumsal iktisat ele alınmıştır. Kurumsal İktisadın tarihsel süreci, Amerikan kurumsalcılığının ortaya çıkışı, yükselişi ve düşüşü çerçevesinde incelenmiştir. Kurumsal İktisat ekolü yekpare olarak alınmamış olup, öncelikle Orijinal-Asıl Kurumsal İktisat; temel özellikleri, yöntemleri ve varsayımları ile Alman Tarihsel Okulu ve Amerikan Pragmatik Felsefe Geleneği bağlamında çözümlenmeye çalışılmıştır. Günümüzün popüler akımı olan Yeni Kurumsal İktisat ise "yeniden yükselen Kurumsal İktisat mi, yoksa yeni bir Kurumsal İktisat mı?" sorusuyla ele alınmaktadır. Bu kapsamda Yeni Kurumsal İktisat yaklaşımının gelişim süreci, metodolojik temelleri ve varsayımları incelenmiştir. Metodolojik bireycilik, sinırlı rasyonellik/akılcılık ve işlem maliyetleri burada ele alınan başlıklar arasındadır. Nihayet Asıl ve Yeni Kurumsal İktisat arasındaki farklılıklar ve benzerlikler üzerine bir çözümleme denemesi ile birinci bölüm kapatılmıştır.

Tezin ikinci bölümünde kurumsal yapıekonomik büyüme ilişkisi teorik çerçevede ele alınmış, kurumların kavramsallaştırılması, tanımları ve türleri ile kurumsal yapının ekonomik büyümeyi ve performansı etkileme kanalları "özgürlükler, demokrasi, mülkiyet hakları, hukuk kuralları, yargı sistemi ve düzenlemeler, kamu sektörünün büyüklüğü, tarih, inanç yapısı ve kültürel kodlar ve sosyal sermaye" üzerinden incelenmiş, kurumsal değişim konusu ele alınmıştır.

Bu bölümde ayrıca kurumsal yapının ölçüm 
yöntemleri indeksler üzerinden ele alınmış olup, literatürde sıklıkla kullanılan Ekonomik Özgürlükler İndeksi-Heritage (The Index of Economic Freedom) ile Dünya Ekonomik Özgürlükler İndeksi-Fraser (Economic Freedom of the World) Metodolojisi ayrintılı olarak incelenmiştir.

Tez, kapsamlı bir literatür incelemesi alt bölümüne de sahip olup, öncelikle kurumsal yapı - büyüme ilişkisi üzerine yapılan uygulamalı çalışmalar genel özellikleri itibariyle değerlendirilmiş ve yine seçilmiş uygulamalı çalışmalar, ulaştıkları sonuçları ile kullandıkları parametreler itibariyle sınıflandırılarak, incelenmiştir.

Tezin son bölümü uygulamaya ayrılmıştır. Havuzlanmış Ortalama Grup Tahmincisi (PMG) yöntemi ile panel veri analizi üzerinden kurumsal yapı-ekonomik büyüme ilişkisi test edilmiştir. Oldukça geniş bir ülke seti yine geniş bir zaman dilimi verisi derlenerek bir araya getirilmiştir. Kapsayıcılığ 1 artırma adına farklı modeller test edilmiştir. Aynı anda hem iktisadi hem de siyasal-toplumsal parametrelerin aynı model içerisindeki sonuçları gözlemlenmiştir. Ülkelerin gelişmişlik durumlarına göre sonuçların farklılaşabileceği riskini bertaraf etme adına ülke grupları itibariyle analiz yöntemi tercih edilmiştir. Farklı uluslararası kurumların farklı indeksleri kullanılarak, bu indeksler arasında da karşılaştırma yapabilme şansı yakalanmıştır.

$\mathrm{Bu}$ çalışmalar neticesinde, kurumsal yapı ile ekonomik büyüme arasındaki ilişkiye ve indekslerin anlamlılığına ilişkin olarak önemli ve farklı bir sonuç elde edilmiştir: Heritage indeksine kıyasla, Fraser İndeksi ile Basın Özgürlüğü genel indeksinde temsil edilen kurum parametrelerinin ekonomik büyüme ile ilişkisinin tüm gelir grupları için hem istatistiksel olarak hem de beklenen etki itibariyle daha güçlü olduğu görülmüştür.

Değişen ve gelişen ekonometrik yöntemler, daha zengin veri havuzları ve veri toplama metotları ile indeksleme yaklaşımlarının bu alandaki analizleri daha da sağ lıklı kılacağ aynı anda çok fazla faktörün çözümlenme- sine imkân vereceği değerlendirilmektedir. Tezde bu girişimin belki de primitif ilk adımlarını, modelleme tercihleri, seçilen veri kaynakları ve ulaşılan sonuçları itibariyle görmek mümkündür. Ayrıca farklı indekslerin kurumsal yapı büyüme ilişkisini açıklama gücü de yapılan uygulamalı çalışmayla ortaya konulabilmiş ve bunlar arasında bir karşılaştırma yapabilme imkânı elde edilmiştir.

Tez şu tasvirle tamamlanmiştır: "Klasik Teoriler bir insanın iskelet yapısın oluşturmaktadir. Ancak ekonomiyi ve inceleme evrenini bu iskelet yapısıyla anlamamız mümkün değildir. Bu bize sadece sinırl bir bilgi sağlar, bir imge verir. Oysa Asıl Kurumsal İktisat ve kismen de olsa Yeni Kurumsal Iktisat, o iskeleti organlarla ve dis yapr ile baştanbaşa kaplar. Organlardaki işlevsel bozukluklara sadece iskelet yapısina ve onun bilgilerine bakarak, çözüm üretemeyiz. Bizatihi o organların, damarların ve hücrelerin bilgi-

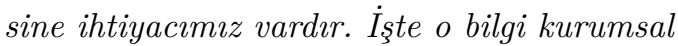
yapılarda ve kurumlarda saklıdır. Açılması gereken kara kutu işte budur ve açılması da işte bu yüzden gereklidir".

\section{Tezin hedef kitlesi}

Tez, ele aldığı konular itibariyle hem iktisat teorisyenlerini hem de iktisat tarihçilerini hedefleyen bir alan örgüsüne sahiptir. Bu nedenle tezin özellikle ilk bölümü, genelde iktisat tarihçileri açısından yüzeysel geçilen bir alanın derinlemesine incelenmesi gerektiğini ortaya koyar. İkinci ve üçüncü bölümler ise büyüme ve kalkınma teorisyenleri ve bu alanda araştırma yapan iktisatçların araştırma alanına hitap etmektedir. 